\title{
Mitteilungen
}

über ben

\section{2Ullgemeinen (நenofienjhaftstag}

des

\author{
Zlllgemeinen Derbandes \\ der auf Selbjthilfe beruhenden Deutfihen Grwerbs= \\ und Wirt[dajtsgenofienfhaften, e. $D$.
}

ju

Sad Jauheim

vom 5. bis 8. Geptember 1910.

$\diamond \diamond \diamond$

Grrausgegeben von dem Allgemeinen Derbande der auf Selbithilfe beruhenden Deutiden Erwerbs: und wirtid̨aftsgenoffenidaften, eingetragener Derein.

$\diamond \diamond \diamond$

Berlin 1910

Kommilfionsperlag von J. Guttentag, 6. m. b. 的.

W. Cügorwitrafie 107/108. 